\title{
Intravenous Isoprenaline and Orciprenaline as a Guide to the Drug Treatment of Stokes-Adams Attacks
}

\author{
DAVID REDWOOD,* M.A., M.B., M.R.C.P.
}

Brit. med. F., 1968, 1, 419-421

The use of sustained-action isoprenaline in the treatment of patients with heart block is well established (Dack and Robbin, 1961 ; Fleming and Mirams, 1963 ; Bluestone and Harris, 1965). Though isoprenaline has less tendency than adrenaline to stimulate ventricular ectopic foci, fatal arrhythmias are produced in some patients, and Bluestone and Harris (1965) have given a preliminary report of the necessity for testing the effect of a brief high blood level of isoprenaline while under close supervision, before embarking on therapy with the sustained-action preparation.

The results of intravenous and oral isoprenaline are reported in 23 patients with heart block and Stokes-Adams attacks. At the same time the opportunity has been taken to compare the effect of isoprenaline and orciprenaline intravenously. Both drugs have positive chronotropic and inotropic effects on the heart and in this respect are similar to adrenaline. In patients with complete heart block isoprenaline and orciprenaline increase both atrial and ventricular rates, but have less tendency than adrenaline to stimulate ventricular ectopic foci. Cardiac output is increased, ejection time is reduced, and there is a fall in atrial pressure (Stack et al., 1958). The depressor effect on the peripheral vascular resistance results in a fall in diastolic pressure with either no change or a slight fall in systolic pressure (Schumacher and Schmock, 1954 ; Spitzbarth and Albers, 1961 ; Palmero, 1965).

The 23 patients were consecutive cases of atrioventricular block admitted to hospital for consideration of pacing who had not had a trial of long-acting isoprenaline in full dosage.

\section{Method}

Reports on the effects of the two drugs on the cardiovascular system have shown that isoprenaline is quantitatively more effective than orciprenaline (Spitzbarth and Albers, 1961), and this has been confirmed by our results. Isoprenaline was used in a concentration of $5 \mathrm{mg}$. of the sulphate diluted in $500 \mathrm{ml}$. of $\mathrm{N}$ saline or $5 \%$ dextrose, giving a drug concentration of 10 $\mu \mathrm{g} . / \mathrm{ml}$., and orciprenaline was used in a concentration of $5 \mathrm{mg}$. in $30 \mathrm{ml}$. of $\mathrm{N}$ saline $(165 \mu \mathrm{g} . / \mathrm{ml}$.).

An intravenous infusion was set up with $\mathrm{N}$ saline or $5 \%$ dextrose, and the bottle containing the diluted drug was connected with a separate giving set. The patients were continuously monitored on an oscilloscope, samples were taken on a direct-writing electrocardiograph throughout the procedure, and close observation was continued for 30 minutes after completion of the infusion. A defibrillator and other equipment for resuscitation was available during the investigations.

Baseline atrial and ventricular rates were recorded on standard lead II (to show $\mathbf{P}$ waves) and the infusion was started at between 15 and 20 drops/minute (giving a concentration of about 10 to $13 \mu \mathrm{g} . / \mathrm{minute}$ of isoprenaline and 150 to 200 $\mu \mathrm{g} . /$ minute of orciprenaline). An E.C.G. was taken at successive increases in drug concentration after a wait of two \footnotetext{
- Research Fellow, Cardiac Department, St. George's Hospital, London
S.W.1.
}

to three minutes to allow the rate increase to stabilize. The drip rate was increased until there was either an appreciable rise in ventricular rate (with isoprenaline at a concentration between 20 and $40 \mu \mathrm{g} . /$ minute and with orciprenaline between 200 and $300 \mu \mathrm{g} . /$ minute) or arrhythmias appeared, in which case the infusion was stopped immediately.

The 23 patients (17 males and 6 females) were aged 8 to 89 , with a mean of 64 years. They all presented with a history of Stokes-Adams attacks and had chronic atrioventricular block, either complete or partial. In order to confirm or contradict the response predicted with intravenous drugs, the majority of the patients were subsequently treated with oral isoprenaline or orciprenaline, and followed up for periods ranging from 3 to 12 months, with a mean of 7 months.

\section{Results of Intravenous Isoprenaline Trial}

\section{Complete Atrioventricular Block}

In all the patients with complete atrioventricular block (13) there was an increase in atrial rate with intravenous isoprenaline, and this served as a convenient index of the potency of the preparation used. There was also an increase in the ventricular rate in all patients, though the degree varied widely (Fig. 1).

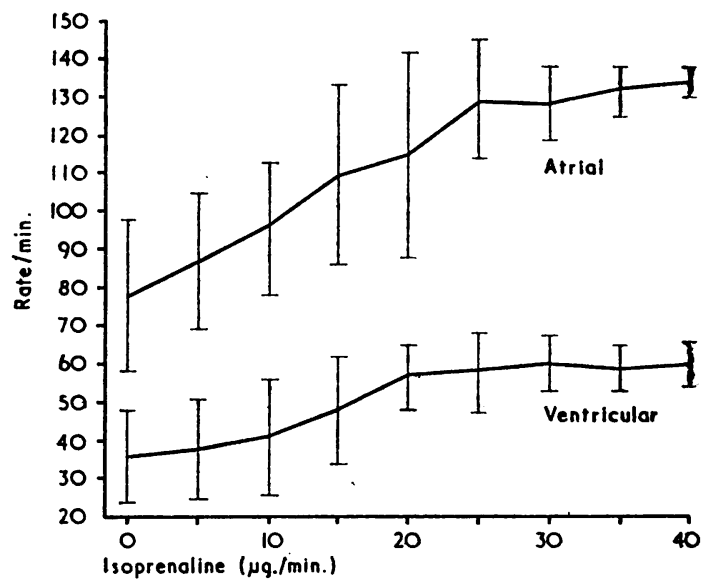

FIG. 1.- Complete atrioventricular block (13 patients). To show the atrial and ventricular rate change with increasing isoprenaline dose. (Mean values, with the range of the rate change shown by the vertical bars.)

Eleven patients had a stable increase in ventricular rate with intravenous isoprenaline, and in six of them intravenous orciprenaline was also used with a similarly satisfactory response (that is to say, a regular ventricular rhythm with up to $30 \mu \mathrm{g} . / \mathrm{minute}$ of isoprenaline and 400 to $500 \mu \mathrm{g} . / \mathrm{minute}$ of orciprenaline). Ten of the 11 patients had an increase in ventricular rate without change in ventricular focus (Fig. 2 a), and in the remaining patient the ventricular focus changed at a dose of $13 \mu \mathrm{g}$./minute of isoprenaline, but this new focus remained stable with further increases in the dose (Fig. $2 \mathrm{c}$ ). All 11 patients remained free from Stokes-Adams attacks on 
oral long-acting isoprenaline, but the one with the change in ventricular focus died unexpectedly six months later.

Two patients showed a poor response to intravenous isoprenaline, one of whom (Fig. 2 b) was also given intravenous orciprenaline with a similarly poor response (that is to say, a changing ventricular focus appeared with less than $30 \mu \mathrm{g} . /$ minute of isoprenaline and with less than 400 to 500 $\mu \mathrm{g} . / \mathrm{minute}$ of orciprenaline). Both these patients continued to have Stokes-Adams attacks on oral long-acting isoprenaline.

The effect of high doses of intravenous isoprenaline is shown in Fig. 2 d. At $40 \mu \mathrm{g}$./minute multiple ventricular ectopic beats appeared with a mean rate of $120 /$ minute. This patient had a stable increase in ventricular rate with up to $30 \mu \mathrm{g} . /$ minute, and, as expected, had no further Stokes-Adams attacks while on oral long-acting isoprenaline in moderate dosage (60 mg. six-hourly) for the 12 months in which he has been followed.
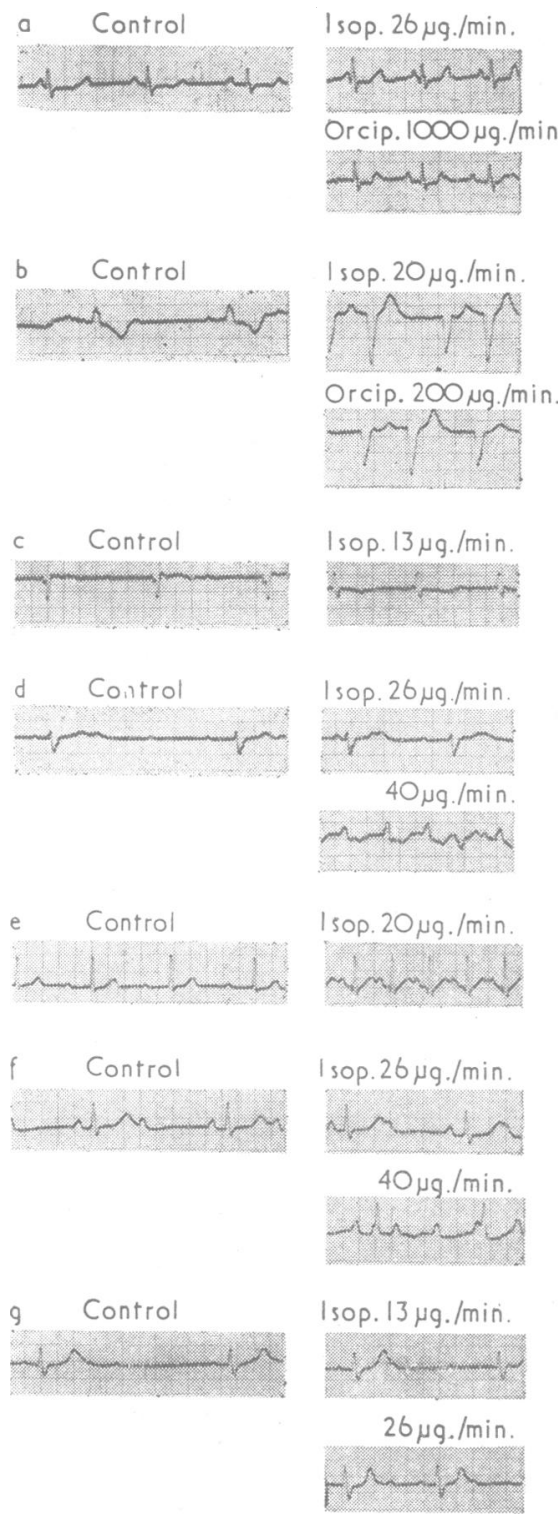

FIG. 2.-Response to intravenous isoprenaline (see text). (a) Stable increase in ventricular rate. (b) Alteration in the ventricutricular rate. (b) Alteration in the ventricular focus with modest doses of isoprenaline and orciprenaline. (c) Change in ventricular focus but remaining stable. (d) Effect of high doses of isoprenaline-multifocal ectopic beats at $40 \mu \mathrm{g}$./minute. (e) Firstdegree atrioventricular block. Reduction in $\mathbf{P}-\mathbf{R}$ interval. (f) $2: 1$ atrioventricular block. Complete heart block appearing at high isoprenaline dose. (g) $2: 1$ atrio ventricular block Complete heart block appearing at low isoprenaline dose.

\section{First-degree Block}

Of the four patients in sinus rhythm one could not tolerate more than $9 \mu \mathrm{g} . /$ minute of isoprenaline because of the tachycardia produced (though even this small dose reduced the P-R interval from 0.24 to 0.2 second); effective doses of oral isoprenaline could not be reached for the same reason and he had to be paced. Two other patients in this group also showed reduction of the P-R interval (Fig. 2 e), and, though in one this occurred only with higher doses of isoprenaline, this patient has responded satisfactorily to oral drugs, while the other had such infrequent attacks that it would be impossible to assess the value of therapy without a very long follow-up. The remaining patient showed no change in the $P-R$ interval with either isoprenaline or orciprenaline and in fact continued to have periods of asystole during the course of the infusionshe was therefore paced.

It is possible, therefore, that a reduction in the P-R interval, representing improved atrioventricular conduction, may imply a favourable response, but often effective doses of oral drugs cannot be reached because of the tachycardia produced, and the usefulness of isoprenaline and orciprenaline is then limited in patients with sinus rhythm.

There was one child-a boy aged 8 with a three-month history of Stokes-Adams attacks thought to be due to myocarditis. He had nodal rhythm with occasional sinus rhythm, and $30 \mathrm{mg}$. of oral long-acting isoprenaline had resulted in atrial flutter with block. Intravenous isoprenaline at a dose of 10 $\mu \mathrm{g}$./minute gave a stable sinus tachycardia at $144 /$ minute with a P-R interval of 0.08 second, and $1.8 \mathrm{mg}$. of atropine had a similar effect. He was given $15 \mathrm{mg}$. six-hourly of oral longacting isoprenaline, and on this dose, though remaining in nodal rhythm, he had no further Stokes-Adams attacks for six months, when the attacks recurred and he had to be paced.

\section{Second-degree Block with Intermittent Complete Block}

There were five patients with second-degree block and intermittent complete block. Not one of these returned to sinus rhythm during the isoprenaline infusion-indeed, four developed complete block with high doses of the drug, associated with an increase in atrial rate (Fig. $2 \mathrm{f}$ and $\mathrm{g}$ ). Only one of these patients remained free from Stokes-Adams attacks on oral long-acting isoprenaline.

\section{Discussion}

The results of the intravenous trial of isoprenaline usually gave an accurate prediction of the value of oral therapy. This was especially so in the patients with complete atrioventricular block. The criterion used for a satisfactory result was a stable increase in ventricular rate with between 20 and $30 \mu \mathrm{g}$./minute of isoprenaline and between 200 and $300 \mu \mathrm{g}$./minute of orciprenaline. On these criteria 10 patients with complete atrioventricular block showed a satisfactory response, and they all remained free from Stokes-Adams attacks on oral long-acting isoprenaline. In a further patient the ventricular focus changed at $13 \mu \mathrm{g}$./minute of intravenous isoprenaline (Fig. $2 \mathrm{c}$ ), and, though there were no further Stokes-Adams attacks for six months, this patient then died unexpectedly, presumably from a Stokes-Adams attack. Two patients showed a poor response to intravenous isoprenaline with the appearance of a changing ventricular focus at less than $30 \mu \mathrm{g}$./minute of isoprenaline. Both these patients continued to have Stokes-Adams attacks on oral long-acting isoprenaline.

Patients in sinus rhythm with Stokes-Adams attacks often do not tolerate effective doses of oral long-acting isoprenaline because of the tachycardia produced, though the attacks should be abolished in those who show improved atrioventricular conduction with intravenous isoprenaline. 
It is more difficult to predict the value of oral long-acting isoprenaline therapy in the group of patients with seconddegree heart block and intermittent complete block. Surprisingly, not one of the five patients in this group returned to sinus rhythm with intravenous isoprenaline-had they done so one would have expected no further Stokes-Adams attacks on oral therapy. In fact four of these patients developed complete atrioventricular block despite high doses of the intravenous drug, and this was probably related to the increase in atrial rate. Of the four, oral long-acting isoprenaline therapy was successful in abolishing Stokes-Adams attacks in only one -in this patient complete heart block had appeared at a low dose of intravenous isoprenaline ( $13 \mu \mathrm{g} . /$ minute), suggesting that oral isoprenaline by increasing the atrial rate induced a stable rhythm (complete block) and thereby protected against further attacks (Fig. 2 g).

In the course of the investigation of the value of intravenous isoprenaline the opportunity was taken to compare the intravenous effects of this drug and orciprenaline. There have been no observable qualitative differences between the effects produced by the two drugs. The results with intravenous isoprenaline in the 13 patients in complete block are shown in Fig. 1 and can be compared with the results in seven of these patients with intravenous orciprenaline (Fig. 3). Isoprenaline is quantitatively between 15 and 20 times more potent in its chronotropic effect on the atria and ventricles than orciprenaline, and ventricular arrhythmias are produced by both drugs with the same quantitative difference.

In order to relate the intravenous dose of isoprenaline to the oral dose of the long-acting preparation, the concentration of intravenous isoprenaline producing an increase in ventricular

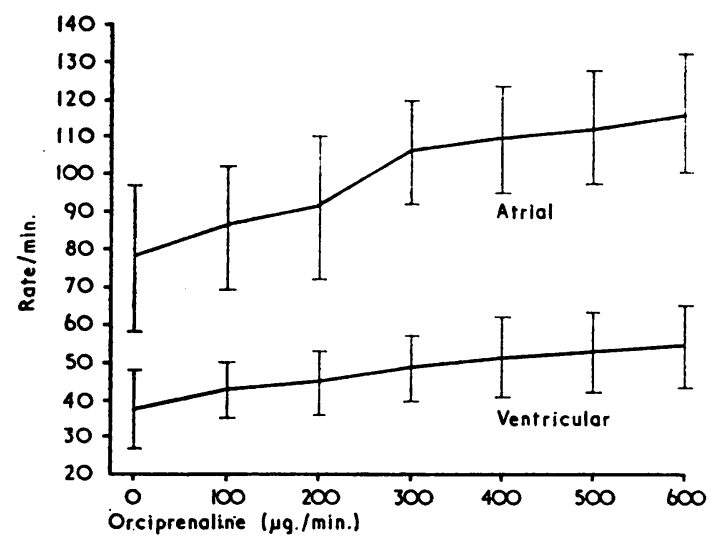

FIG. 3.-Complete atrioventricular block. To show the atrial and ventricular rates with increasing orciprenaline dose in seven patients. (Mean values, with the range of the rate change shown by the vertical bars.)

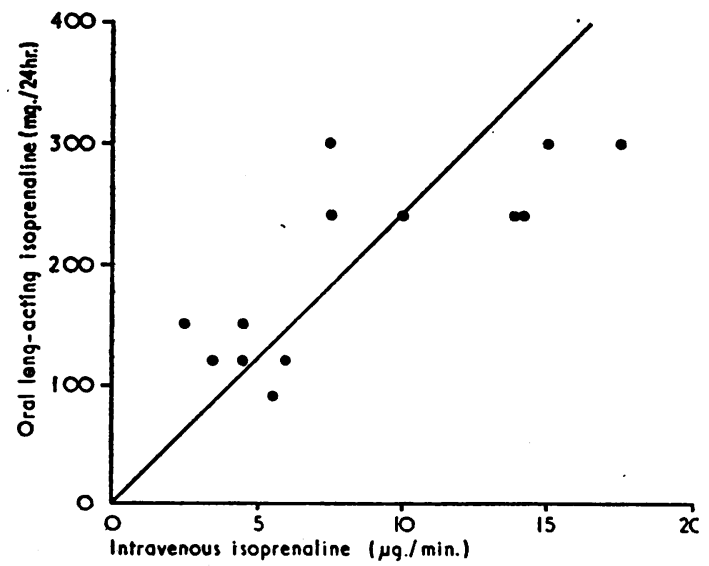

FIG. 4.-Complete atrioventricular block (13 patients) Dose of oral long-acting isoprenaliine producing an increase in ventricular rate of $5 /$ minute plotted against the dose of intravenous isoprenaline producing the same rate change. rate of five beats per minute has been plotted in Fig. 4 against the daily dose of long-acting isoprenaline which produced the same increase in rate. This gives only a very approximate guide to the oral dose of the drug, because, firstly, the rate change with increasing doses of isoprenaline intravenously is not linear (Fig. 1), and, secondly, the ventricular rate in patients on oral therapy varies during the day, this probably being due to variable absorption of the drug. Allowing for these inaccuracies, there appears to be a relation between the effect of intravenous and oral isoprenaline that is useful in estimating the daily dose of the oral preparation, and it is seen that a $5 /$ minute ventricular rate increase with an infusion of $5 \mu \mathrm{g} . /$ minute of isoprenaline is associated with an oral dose of about $120 \mathrm{mg}$./day (30 mg. six-hourly), while a similar rate increase with $15 \mu \mathrm{g} . / \mathrm{minute}$ is associated with an oral dose of 300 $\mathrm{mg}$./day (60 mg. four-hourly, omitting the night dose).

\section{Summary}

In 23 patients with heart block and Stokes-Adams attacks the effect of a brief and closely supervised infusion of intravenous isoprenaline was studied in order to assess the patients' suitability for oral long-acting isoprenaline. If arrhythmias, which are the likely precursors of ventricular fibrillation, appear at modest doses of the drug (isoprenaline 10-20 $\mu \mathrm{g} . /$ minute) therapy with oral long-acting isoprenaline will be dangerous.

The most satisfactory results were obtained in those patients with complete atrioventricular block, when the response to the intravenous drug predicts the response to oral therapy with reasonable accuracy.

No accurate prediction of the value of oral long-acting isoprenaline can be given in patients in first- and second-degree atrioventricular block.

The results of a comparison made between intravenous isoprenaline and orciprenaline show no qualitative differences between the two drugs, but isoprenaline is quantitatively between 15 and 20 times more potent than orciprenaline in its chronotropic effects on the atria and ventricles.

I am indebted to Dr. Aubrey Leatham for his advice and help in the preparation of this paper.

\section{Bibliography}

Ahlquist, R.P. (1948). Amer. f. Physiol., 153, 586.

Benchimol, A., Lucena, E. G., and Dimond, E. G. (1965). Circulation, 31, 417.

337.

Bluestone, R., and Harris, A. (1965). Lancet, 1, 1299.

Dack, S., and Robbin, S. R. (1961). J. Amer. med. Ass., 176, 505.

Fleming, H. A., and Mirams, J. A. (1963). Lancet, 2, 214.

Friese, G., and Thorspecken, R. (1961). Disch. med. Wschr., 86, 1045.

Greiner, T. H., and Garb, S. (1950). 7. Pharmacol. exp. Ther., 98, 215.

Heinecker, R., and Liesser, G. (1962). Med. Welt (Stuttg.), 1, 807.

Johansson, B. W. (1961). Amer. 7. Cardiol., 8, 76.

Jones, R. J. (1958). \%. Amer. med. Ass., 167, 1840.

Kaufman, J., Iglauer, A., and Herwitz, G. K. (1951). Amer. F. Med., 11, 442.

Nathanson, M. H., and Miller, H. (1949). Proc. Soc. exp. Biol. (N.Y.), 70. 633.

- - (1950a). Amer. Heart 7., 40, 374.

- (1950b). Calif. Med., 72, 215.

- (1952). Circulation, 6, 238.

Palmero, H. A. (1965). Amer. Heart f., 70, 449.

Robbin, S. R., Goldfein, S., Schwartz, M. J., and Dack, S. (1955). Amer. \}. Med., 18, 577.

Schmidt-Voight, J. (1961). Med. Welt (Stuttg.), 2, 2416.

Schumacher, E. E., and Schmock, C. L. (1954). Amer. Heart F., 48, 933. Spitzbarth, H., and Albers, P. (1961). Arzneimittel-Forsch., 11, 528.

Stack, M. F., Rader, B., Sobol, B. J., Farber, S. J., and Eichna, L. $\mathbb{}$. (1958). Circulation, 17, 526.

Zoll, F. M., Linenthal, A. J., Gibson, W., Paul, M. H., and Norman, L. R. (1958). Ibid., 17, 325. 